\title{
Using Microseismicity to Estimate Formation Permeability for Geological Storage of $\mathrm{CO}_{2}$
}

\author{
D. A. Angus ${ }^{1}$ and J. P. Verdon ${ }^{2}$ \\ ${ }^{1}$ CiPEG, University of Leeds, Leeds LS2 9JT, UK \\ ${ }^{2}$ School of Earth Sciences, University of Bristol, Bristol BS8 1RJ, UK \\ Correspondence should be addressed to D. A. Angus; d.angus@leeds.ac.uk
}

Received 18 December 2012; Accepted 4 January 2013

Academic Editors: E. Del Pezzo and A. Donnellan

Copyright @ 2013 D. A. Angus and J. P. Verdon. This is an open access article distributed under the Creative Commons Attribution License, which permits unrestricted use, distribution, and reproduction in any medium, provided the original work is properly cited.

\begin{abstract}
We investigate two approaches for estimating formation permeability based on microseismic data. The two approaches differ in terms of the mechanism that triggers the seismicity: pore-pressure triggering mechanism and the so-called seepage-force (or effective stress) triggering mechanism. Based on microseismic data from a hydraulic fracture experiment using water and supercritical $\mathrm{CO}_{2}$ injection, we estimate permeability using the two different approaches. The microseismic data comes from two hydraulic stimulation treatments that were performed on two formation intervals having similar geological, geomechanical, and in situ stress conditions, yet different injection fluid was used. Both approaches (pore-pressure triggering, and the seepage-force triggering) provide estimates of permeability within the same order of magnitude. However, the seepage-force mechanism (i.e., effective stress perturbation) provides more consistent estimates of permeability between the two different injection fluids. The results show that permeability estimates using microseismic monitoring have strong potential to constrain formation permeability limitations for large-scale $\mathrm{CO}_{2}$ injection.
\end{abstract}

\section{Introduction}

Fracture stimulation has been applied for the past 60 years to enhance recovery from hydrocarbon reservoirs, with an estimated $70 \%$ of wells being fracture stimulated, and hence is a key factor in the economic exploitation of unconventional reserves, such as tight-gas and shale-gas reservoirs [1]. Over the past 20 years, microseismic monitoring has developed into one of the most effective methods of monitoring fracture stimulation and hence is routinely applied to monitor fracture stimulation programs.

The spatial and temporal variations in microseismicity can be used to monitor changes in the stress field and hence potentially be used to monitor perturbations in fluid pathways as well as top-seal and well-bore integrity. Furthermore, microseismicity has been used also to characterise spatial and temporal variations within the reservoir and surrounding rock mass by monitoring changes in seismic attributes between the source and receiver (e.g., shear-wave splitting analysis to characterise fracture-induced anisotropy [2-4]).
Additional information can be gained by evaluating microseismic failure mechanisms to characterise the rock mass at the source and provide a measure of the strength, orientation, and type of elastic failure to potentially quantify damage (e.g., [5-7]).

Although microseismicity can provide fairly accurate temporal and spatial locations of brittle failure, how the measured microseismicity relates to the evolution of the induced pressure front and effective stress field as well as creation and enhancement of cracks and fractures is still not well constrained. Examination of the distribution of microseismic events can help characterize the flow and mechanical properties of the stimulated reservoir. In particular, by assuming that seismicity is triggered by the diffusion of porepressure from the injection point, Shapiro [8] has shown that the permeability of a formation can be estimated from the rate of increase in distance between injection well and event hypocenter distance through time. This spatiotemporal behaviour is commonly visualized on the so-called $r$ - $t$ plot, (where $r$ is injection-well-to-event distance and $t$ is time). 
This method has shown potential for predicting apparent formation permeability and hydrocarbon production for various fracture stimulation case studies (e.g., [9]).

Although this pore-pressure diffusion approach has shown some promise in estimating reservoir permeability, there are some nonphysical aspects to the theory, such as weak pore-pressure perturbation triggering seismicity [10]. As an alternative to the pore-pressure diffusion approach, Rozhko [11] introduces the concept of seepage-force triggering to predict the $r$ - $t$ response of seismicity, which considers diffusion of effective stress perturbations as the driving force of microseismicity.

In this paper we compare both methods, predicting formation permeability by modelling observed $r$ - $t$ behaviour during hydraulic fracturing, where water and supercritical $\mathrm{CO}_{2}$ have been used as the injected fluids. By estimating permeability using microseismic monitoring, we hope to explore the potential of using microseismic monitoring to constrain formation permeability limitations for large-scale $\mathrm{CO}_{2}$ injection sites.

\section{Models Describing Spatiotemporal Evolution of Seismicity}

2.1. Pore-Pressure Triggering. The $r$ - $t$ pore-pressure triggering approach is based on the concept that the spatial and temporal evolution of microseismicity is hydraulically induced and characterised in terms of a low frequency porepressure relaxation mechanism described by Biot [12]. The key assumption for application of this approach to hydraulic fracture-induced microseismic data is that the tectonic stress in the subsurface is close to the critical stress needed for brittle failure (e.g., [13]). As such, increasing fluid pressure (i.e., injecting fluid) within the reservoir results in a transient increase of the reservoir pore-pressure and a decrease in effective stress. If the decrease in effective stress is sufficient, it can lead to relaxation of normal stresses along preexisting fractures and hence slip along the fracture and associated microseismicity. The following derivations are from Shapiro [8] and so the reader is referred to this paper for a more detailed presentation of the approach.

Assuming a point-source injector and a homogeneous and isotropic medium, the triggering front (i.e., the distance between outer enveloe of the microseismic "cloud" and the fluid injection point) is described by

$$
r(t)=\sqrt{4 \pi D\left(t-t_{o}\right)},
$$

where $t$ is observation time, $t_{0}$ is injection start time, and $D$ is the scalar apparent hydraulic diffusivity. By plotting the microseismic events on a time-distance plot and matching the best-fitting $r$ - $t$ curve to the triggering front an estimate of the hydraulic diffusivity can be obtained. The calculated apparent diffusivity can then be used to estimate other reservoir and flow parameters, such as formation permeability.

Assuming that the injected fluid is incompressible, the fluid volume balance is such that the total injected fluid is equal to the sum of the fluid volume within the fracture and lost to the surrounding formation. Further, assuming that the induced fracture is straight and of fixed height (i.e., the PKN model; see [14]), then the fracture half-length is approximated by

$$
L(t) \approx \frac{q_{i} t}{4 h_{f} C_{l} \sqrt{2 t}+2 h_{f} w},
$$

where $q_{i}$ is the average injection rate, $h_{f}$ is the fracture height (either estimated from perforation interval or vertical extent of microseismicity), $C_{l}$ is the fluid-loss coefficient, and $w$ is the average fracture width. The fluid-loss coefficient $C_{l}$ is given by

$$
C_{l} \approx \frac{q_{i}}{8 h_{f} \sqrt{2 \pi D}}
$$

Another surface, the back front, characterises the seismically quiet zone after injection stops and tracks the propagation of maximum pore-pressure perturbation. The back front is given by

$$
r_{b}(t)=\sqrt{2 d D t\left(\frac{t}{t_{s}}-1\right) \ln \left(\frac{t}{t-t_{s}}\right)},
$$

where $d$ is the dimension of the pressure diffusion $(1 \mathrm{D}, 2 \mathrm{D}$, or $3 \mathrm{D})$ and $t_{s}$ is the injection shut-off time.

Neglecting induced fracture surface effects such as filter cake permeability damage and effects on pore space and fractures within the vicinity of the fracture treatment, the permeability of the reservoir can be estimated:

$$
\kappa \approx \frac{q_{i}^{2} \mu_{f}}{128 h_{f}^{2} \Delta p^{2} \phi c_{f} D},
$$

where $c_{f}$ and $\mu_{f}$ are the compressibility and viscosity of the reservoir fluid, respectively, $\Delta p$ is the difference in the average injection pressure and the initial (or far-field) reservoir pressure, and $\phi$ is the reservoir porosity.

2.2. Seepage-Force Triggering. The nonlinear diffusion approach of Shapiro [8] and the so-called Coulomb failure stress (CFS) criteria (e.g., [15]) applied to microseismicity make the assumption that seismicity is triggered by the propagation of a fluid pressure perturbation front. Based on the previous mechanism, it is implied that small changes in pore-pressure are sufficient to trigger seismicity, and this is often explained by assuming that most of the faults are critically stressed [13, 15]. Rozhko [11] argues that induced microseismicity is explained and predicted better by linear diffusion coupled to linear poroelastic deformation rather than the highly nonlinear fluid diffusion mechanism [8] or CFS and critically stressed faults [15].

In the Rozhko [11] approach, the seismicity is triggered by the propagation of an effective stress perturbation front. The role of fluid pressure in rock strength is significant, yet comes about through the Terzaghi [16] effective stress law

$$
\underline{\sigma}_{i j}=\sigma_{i j}+\delta_{i j} P
$$


where $\underline{\sigma}_{i j}$ is the effective stress tensor, $\sigma_{i j}$ is the stress tensor, $P$ is pressure, and $\delta_{i j}$ is the Kronecker delta function. Rozhko [11] refers to this as the so-called seepage-force and makes use of the Coulomb yielding criteria (CYS) written as

$$
\mathrm{CYS}=\frac{\sigma_{1}-\sigma_{3}}{2}+\sin \phi_{y}\left(\frac{\sigma_{1}+\sigma_{3}}{2}+P\right)+C_{y} \cos \phi_{y},
$$

where CYS is the Coulomb yielding stress and $\sigma_{1}$ and $\sigma_{3}$ are the maximum and minimum principal stresses (positive in tension). The parameters $\phi_{y}$ and $C_{y}$ are the friction angle and cohesion during dilatancy and can be determined from geomechanical triaxial laboratory measurements. Application of CYS stems from laboratory measurements, where observed acoustic emissions during loading have been shown to correlate with the onset of dilatancy. CYS not only describes the onset of dilatancy and hence microseismicity, but also incorporates the Kaiser effect [17]; during unloading deformation is elastic with no additional fracturing, and during reloading no additional fracturing and seismicity develop until overcoming the previous loading maximum.

The seismicity-triggering front (the CYS equivalent to (1)) is given by

$$
\begin{aligned}
\Delta \mathrm{CYS}= & \frac{1}{r} P_{c 0} H\left(t-t_{0}\right) \\
& \times\left[\eta f_{D}\left(R_{0}\right)+\left(\eta f_{M}\left(R_{0}\right)+f_{F}\left(R_{0}\right)\right) \sin \phi_{y}\right] \\
& +\cdots+\frac{1}{r} P_{c 1} H\left(t-t_{1}\right) \\
& \times\left[\eta f_{D}\left(R_{1}\right)+\left(\eta f_{M}\left(R_{1}\right)+f_{F}\left(R_{1}\right)\right) \sin \phi_{y}\right],
\end{aligned}
$$

where $r$ is radial distance, $\eta$ is the poroelastic stress coefficient, $f_{F}(R), f_{D}(R)$, and $f_{M}(R)$ are nondimensional functions given by Rozhko [11, equations 7, 10, and 11], $R=r /(4 D t)^{1 / 2}$, $P_{c 0}$ and $P_{c 1}$ are the pressure perturbations for times $t_{0}$ and $t_{1}$, $R_{0}=r /\left[4 D_{0}\left(t-t_{0}\right)\right]^{1 / 2}$ and $R_{1}=r /\left[4 D_{1}\left(t-t_{1}\right)\right]^{1 / 2}$, and $D$ is the pressure diffusivity constant. The seismicity-suppression front (the CYS equivalent to (4)) is written as

$$
\begin{aligned}
\Delta \mathrm{CYS}_{*}= & \frac{1}{r} P_{c 0} H\left(t-t_{0}\right) \\
& \times\left[\eta f_{D}\left(R_{0}\right)+\left(\eta f_{M}\left(R_{0}\right)+f_{F}\left(R_{0}\right)\right) \sin \phi_{y}\right] \\
& +\cdots+\frac{1}{r} P_{c 1} H\left(t-t_{1}\right) \\
& \times\left[-\eta f_{D}\left(R_{1}\right)+\left(\eta f_{M}\left(R_{1}\right)+f_{F}\left(R_{1}\right)\right) \sin \phi_{y}\right] .
\end{aligned}
$$

By fitting the seismicity-triggering and seismicity-suppression fronts to the induced seismicity, the formation diffusivity can be estimated. Apparent permeability can then be estimated from

$$
\kappa=D \mu_{f} \varphi\left(c_{m}+c_{f}\right),
$$

where $c_{m}$ is the pore volume compressibility.

\section{Microseismic Data}

Verdon et al. [20] compared the microseismicity produced when first water and then $\mathrm{CO}_{2}$ (in a supercritical state) were used as the injection fluids for hydraulic fracture of a tight gas reservoir, with the purpose of identifying any characteristic differences in event locations and/or magnitudes induced by the different fluids. A total of 9 injection stages were performed in a vertical well, with each stage at a slightly shallower depth than the previous stage (see Maxwell et al. [21]). The first 7 stages used water, while the final 2 used supercritical $\mathrm{CO}_{2}$. No major lithologic differences have been identified between the stages. The fracture stimulations were monitored with a downhole array of 12 three-component geophones installed in a nearby vertical well. Verdon et al. [20] presented data from stages 4 (water) and $8\left(\mathrm{CO}_{2}\right)$. For both fluids, microseismic event locations indicated the formation of fracture networks parallel to the maximum horizontal stress (Figure 1). Event magnitudes showed a weak correlation with injection pressure, while the influence of the differing fluids was found to be minimal.

\section{Permeability Estimates from Pore-Pressure and Seepage-Force Triggering}

\subsection{Pore-Pressure Triggering}

4.1.1. Water-Gel Injection. Figure 1(a) displays a map view of the recorded microseismicity during the water-gel fracture treatment. The microseismicity follows an approximately linear trend with an absolute correlation coefficient of 0.83 using simple linear regression. The length and width of the microseismic cloud are approximately $220 \mathrm{~m}$ and $70 \mathrm{~m}$. In Figure 2, the microseismic events are plotted with respect to distance from injection well and injection time (i.e., $r$ $t$ space). The vertical error bars represent the estimated location errors based on the residuals between the predicted and observed travel times. The events were located using the in-house location algorithm of Pinnacle Technologies (see Zimmer et al. [22]) using an isotropic one-dimensional velocity model (see Figure 3). Also shown are horizontal error bars that serve as a qualitative (and not quantitative) measure of event measurement confidence and so by no means reflect error in time (see Zimmer et al. [22] for description of uncertainty characterization). In other words, they attempt to present additional information about microseismic event quality to help further scrutinize the $r$ - $t$ plot. Three microseismic trigger (or forward front) $r$ - $t$ curves are shown for apparent diffusivities of $1.25 \mathrm{~m}^{2} / \mathrm{s}, 0.60 \mathrm{~m}^{2} / \mathrm{s}$, and $0.40 \mathrm{~m}^{2} / \mathrm{s}$ using (1). These curves represent subjective end-member $r$ $t$ curves for the forward front microseismicity. Also shown is an $r$ - $t$ curve for the back front for an apparent diffusivity of $0.10 \mathrm{~m}^{2} / \mathrm{s}$ using (4).

4.1.2. Supercritical $\mathrm{CO}_{2}$ Injection. Figure 1(b) displays a map view of the recorded microseismicity during the supercritical $\mathrm{CO}_{2}$ fracture treatment. The microseismicity follows a more diffuse trend compared with the water-gel treatment with an absolute correlation coefficient of 0.65 . The length and 


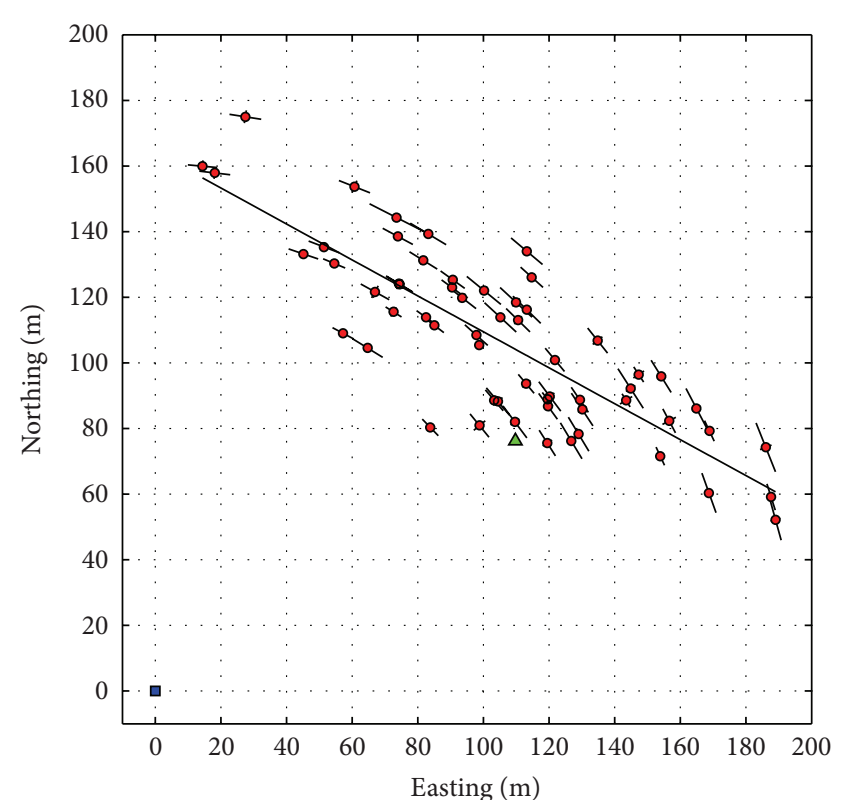

- Recording well

$\Delta$ Injection well

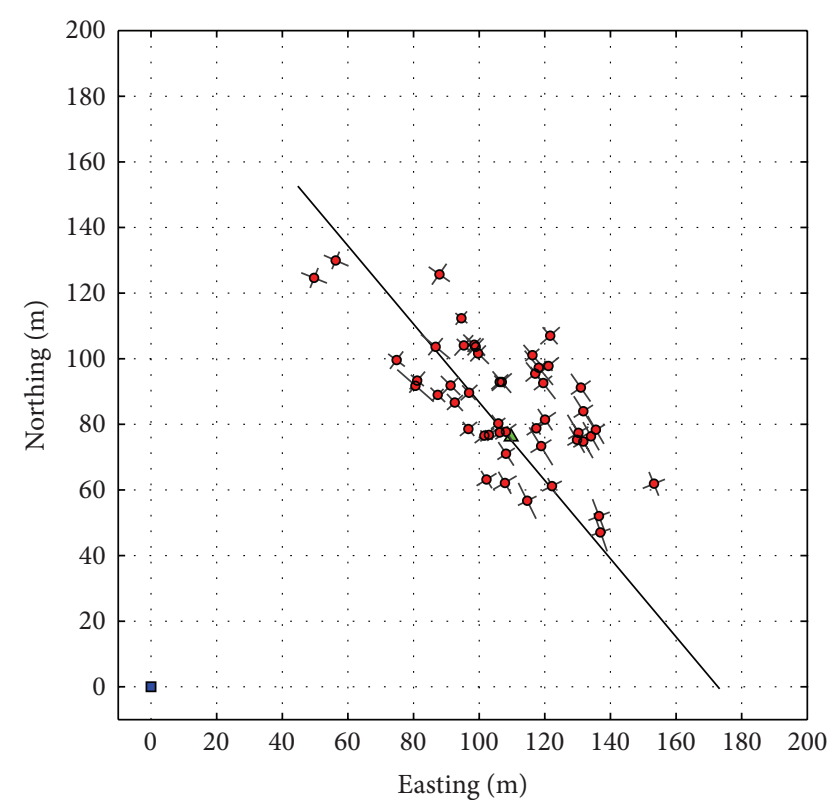

- Recording well

$\Delta$ Injection well

(a)

(b)

FIGURE 1: Map views of event locations during hydraulic fracture stimulation for water (a) and $\mathrm{CO}_{2}$ (b) fluid injection. The locations of the injection well and monitoring array are also marked. Error bars represent one-standard-deviation errors based on arrival time residuals and particle motion analysis. As such, they do not account for the additional errors introduced by velocity model discrepancies (e.g., [18, 19]) and so should be considered a lower bound of the true location error.

width of the microseismic cloud are approximately $120 \mathrm{~m}$ and $50 \mathrm{~m}$. In Figure 4, the microseismic events are plotted in $r-t$ space. Three forward front $r$ - $t$ curves are shown for apparent diffusivities of $1.20 \mathrm{~m}^{2} / \mathrm{s}, 0.80 \mathrm{~m}^{2} / \mathrm{s}$, and $0.30 \mathrm{~m}^{2} / \mathrm{s}$ and a back front $r$ - $t$ curve for an apparent diffusivity of $0.90 \mathrm{~m}^{2} / \mathrm{s}$.

4.2. Seepage-Force Triggering. Figures 5 and 6 show the same observed $r$ - $t$ data with the predicted seismicity-triggering and seismicity-suppression fronts based on seepage-force modelling. In these figures, we assume $\phi_{y}=30^{\circ}$ and $\eta=$ 0.30 . For the water treatment (Figure 5), we use an average differential injection pressure of $14 \mathrm{MPa}$ to define $P_{c 0}=$ $14 \mathrm{MPa}$ and $P_{c 1}=-14 \mathrm{MPa}$. The best fitting seismicitytriggering and seismicity-suppression fronts were obtained using the following values: perforation interval of $20 \mathrm{~m}$, $\Delta \mathrm{CYS}_{h}=0.1 \mathrm{MPa}, D_{0}=2.75 \times 10^{3} \mathrm{~m}^{2} / \mathrm{h}$ and $D_{1}=3.85 \times$ $10^{3} \mathrm{~m}^{2} / \mathrm{h}$. For the supercritical $\mathrm{CO}_{2}$ treatment (Figure 6), we use an average differential injection pressure of $15 \mathrm{MPa}$ to define $P_{c 0}=15 \mathrm{MPa}$ and $P_{c 1}=-15 \mathrm{MPa}$. The best fitting seismicity-triggering and seismicity-suppression fronts were obtained using the following values: perforation interval of $20 \mathrm{~m}, \Delta \mathrm{CYS}_{h_{2}}=0.1 \mathrm{MPa}, D_{0}=2.15 \times 10^{3} \mathrm{~m}^{2} / \mathrm{h}$, and $D_{1}=$ $3.75 \times 10^{3} \mathrm{~m}^{2} / \mathrm{h}$.

\subsection{Permeability Estimates}

4.3.1. Pore-Pressure Triggering. The average reservoir porosity is assumed to be 10\% (an upper end for tight sand reservoirs). The reservoir fluid viscosity and compressibility are estimated to be $1.00 \times 10^{-3} \mathrm{~Pa} \cdot \mathrm{s}$ and $1.45 \times 10^{-11} \mathrm{~Pa}^{-1}$, respectively, based on typical values for oil given by Dake [23]. For the water-gel treatment, the average injection rate is $0.09 \mathrm{~m}^{3} / \mathrm{s}$, the pressure difference $15 \mathrm{MPa}$, and fracture height $70 \mathrm{~m}$. For the supercritical $\mathrm{CO}_{2}$ treatment, the average injection rate is $0.08 \mathrm{~m}^{3} / \mathrm{s}$, the pressure difference $15 \mathrm{MPa}$, and fracture height $100 \mathrm{~m}$. We assume a fracture width of $0.01 \mathrm{~m}$ for both fracture stimulations. Table 1 compiles the results for the estimated fluid-loss coefficient (3), fracture half-length (2), and reservoir permeability (5).

4.3.2. Seepage-Force Triggering. Assuming that the pore volume compressibility is negligible with respect to the reservoir fluid compressibility (i.e., $C_{m} \ll C_{f}$ ), the permeability estimates based on (10) are summarized in Table 2. The assumption of negligible pore volume compressibility suggests that our estimates of formation permeability are conservative (i.e., an underestimate).

Estimates of apparent permeability from both approaches are within the same order of magnitude between $10 \mathrm{mD}$ and $100 \mathrm{mD}$. Note that we use the term "apparent" permeability for two reasons. First, the permeability estimates are typically higher than the true formation permeability through enhancement via hydraulic stimulation. Second, the apparent permeability is indirectly calculated from microseismic data and depends on assumed values of Biot's constant, Poisson's ratio, and the internal angle of friction. 


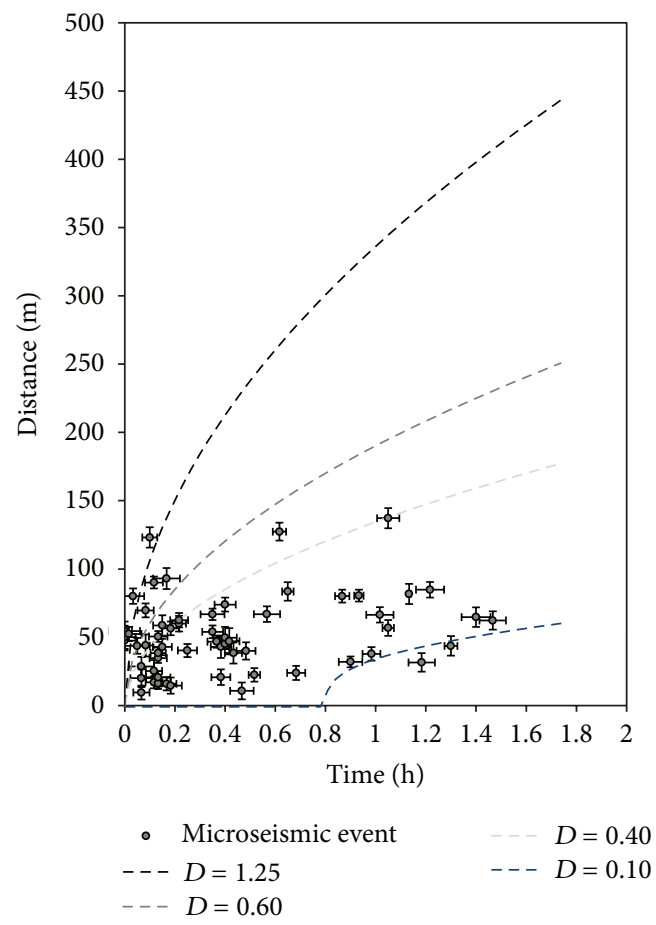

FIGURE 2: $r$ - $t$ pore-pressure triggering plot for water-gel injection treatment. The circles represent the spatiotemporal location of each microseismic event, with the vertical error bar being the total estimated location error and the horizontal error bar representing a scaled event confidence term. The black, the grey, and the lightgrey curves are the triggering front $r$ - $t$ curves for diffusivities of 1.25, 0.60 , and $0.40 \mathrm{~m}^{2} / \mathrm{s}$, respectively. The blue curve is the back front $r-t$ curve with diffusivity of $0.10 \mathrm{~m}^{2} / \mathrm{s}$.

TABLE 1: Estimated fluid loss, fracture half-length, and formation permeability based on pore-pressure triggering.

\begin{tabular}{lcccc}
\hline $\begin{array}{l}\text { Fracture } \\
\text { treatment fluid }\end{array}$ & $\begin{array}{c}\text { Diffusivity } \\
\left(\mathrm{m}^{2} / \mathrm{s}\right)\end{array}$ & $C_{l}\left(\mathrm{~m} / \mathrm{s}^{1 / 2}\right)$ & $\begin{array}{c}L(t) \\
(\mathrm{m})\end{array}$ & $\kappa(\mathrm{mD})$ \\
\hline \multirow{3}{*}{ Water-gel } & 1.25 & $5.91 \times 10^{-5}$ & 108.80 & 34.07 \\
& 0.60 & $8.53 \times 10^{-5}$ & 93.19 & 70.99 \\
& 0.40 & $1.04 \times 10^{-5}$ & 84.33 & 106.48 \\
\hline \multirow{2}{*}{$\mathrm{CO}_{2}$} & 1.20 & $3.68 \times 10^{-5}$ & 79.59 & 14.54 \\
& 0.80 & $4.73 \times 10^{-5}$ & 73.41 & 21.81 \\
& 0.30 & $7.72 \times 10^{-5}$ & 57.91 & 58.15 \\
\hline
\end{tabular}

TABLE 2: Estimated formation permeability based on seepage-force triggering.

\begin{tabular}{llc}
\hline Fracture treatment fluid & $\begin{array}{l}\text { Diffusivity } \\
\left(10^{3} \mathrm{~m}^{2} / \mathrm{h}\right)\end{array}$ & $\kappa(\mathrm{mD})$ \\
\hline \multirow{2}{*}{ Water-gel } & $D_{0}=2.75$ & 67 \\
& $D_{1}=3.85$ & 94 \\
\hline $\mathrm{CO}_{2}$ & $D_{0}=2.15$ & 53 \\
& $D_{1}=3.75$ & 92 \\
\hline
\end{tabular}

For the water-gel fluid injection, the formation permeability estimates based on pore-pressure triggering range

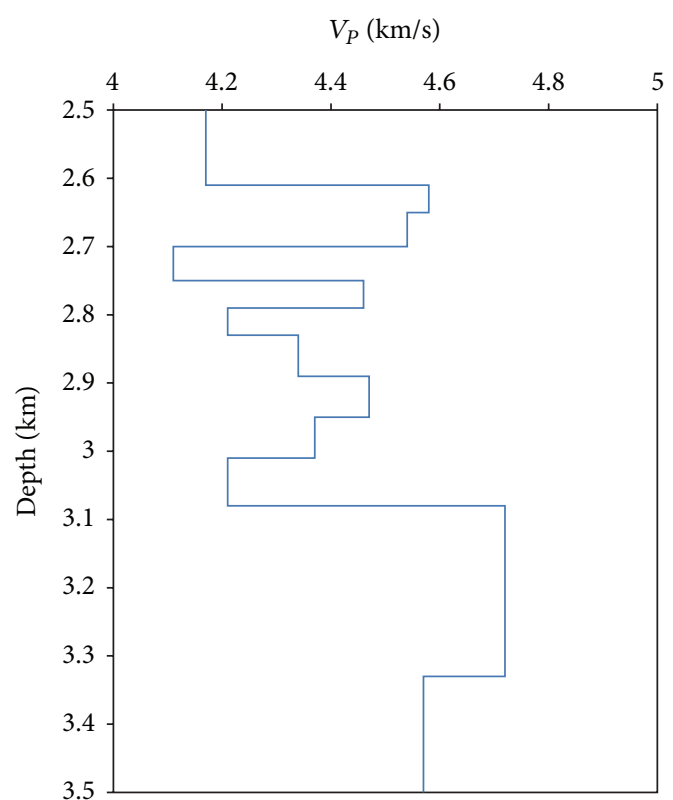

(a)

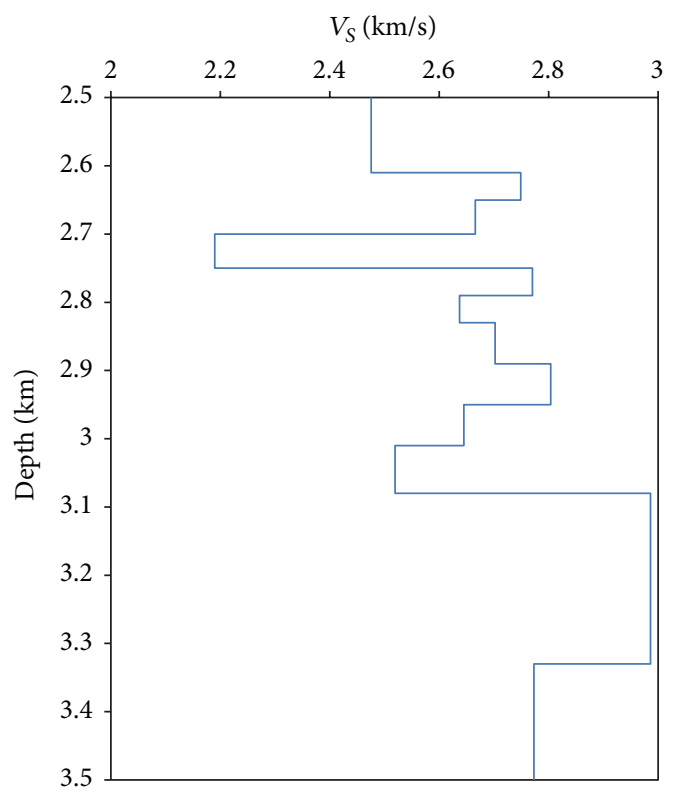

(b)

FIgURE 3: One-dimensional isotropic $P$-wave velocity profile (a) and $S$-wave velocity profile (b) used for locating the microseismic events (the $S$-wave velocity model shows similar structure).

between $34 \mathrm{mD}$ and $106 \mathrm{mD}$, whereas those based on seepage-force triggering range between $67 \mathrm{mD}$ and $94 \mathrm{mD}$. For seepage-force triggering, there are two estimates for formation permeability. This is because two values of diffusivity were needed to fit the microseismic data: $D_{0}$ for the diffusivity during hydraulic stimulation and $D_{1}$ for the diffusivity due to negative pore-pressure perturbation in fractured rock. Thus, the estimate of $\kappa=67 \mathrm{mD}$ during hydraulic stimulation is more representative of formation permeability during fluid injection, whereas the estimate of $\kappa=94 \mathrm{mD}$ is more representative of the formation after fracture damage. For the 


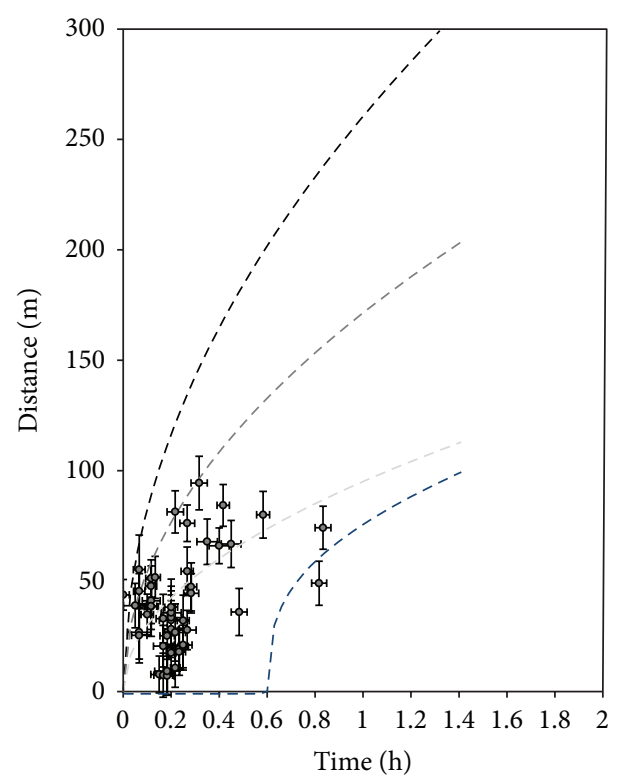

$$
\begin{aligned}
\text { - } & \text { Microseismic event } \\
---D=1.20 & --D=0.30 \\
---D=0.80 &
\end{aligned}
$$

FIGURE 4: $r$ - $t$ pore-pressure triggering plot for supercritical $\mathrm{CO}_{2}$ injection treatment (refer to Figure 2 for details). The black, the grey, and the light-grey curves are the triggering front $r$ - $t$ curves for diffusivities of $1.20,0.80$, and $0.30 \mathrm{~m}^{2} / \mathrm{s}$, respectively. The blue curve is the back front $r$ - $t$ curve for diffusivity of $0.90 \mathrm{~m}^{2} / \mathrm{s}$.

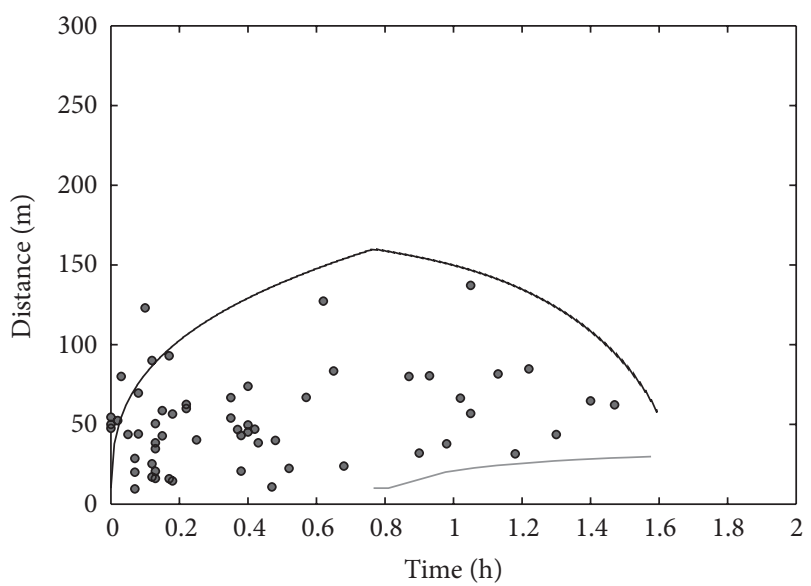

FIGURE 5: $r$ - $t$ seepage-force predictions for the water treatment injection. The black curve is the seismicity-triggering front and the grey curve is the seismicity-suppression front.

supercritical $\mathrm{CO}_{2}$ fluid injection, the formation permeability estimates based on pore-pressure triggering are lower and range between $14 \mathrm{mD}$ and $58 \mathrm{mD}$, whereas those based on seepage-force triggering range between $53 \mathrm{mD}$ and $92 \mathrm{mD}$. Permeability estimates based on seepage-force triggering are more consistent between the water-gel and supercritical $\mathrm{CO}_{2}$ injection. The permeability estimates for the fractured formation are nearly equal as would be expected for similar geological formations. As per the conclusions of Verdon et al.

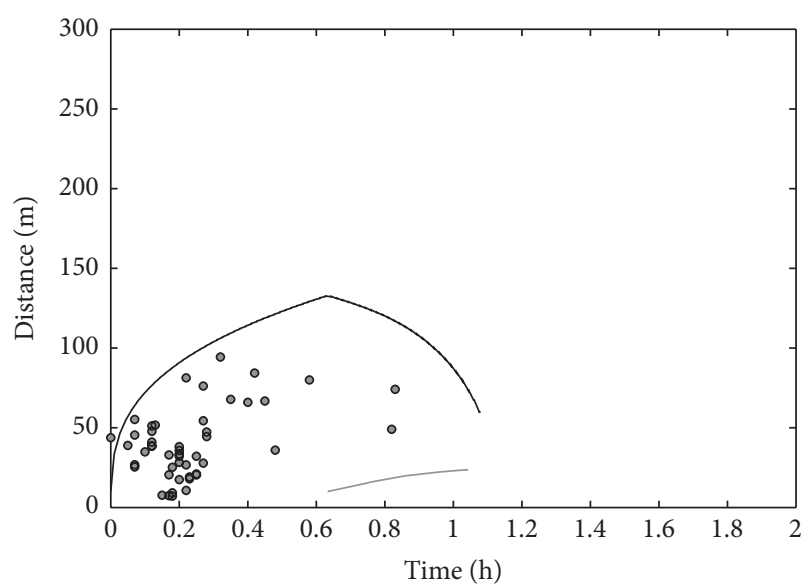

FIGURE 6: $r$ - $t$ seepage-force predictions for the supercritical $\mathrm{CO}_{2}$ injection treatment. The black curve is the seismicity-triggering front and the grey curve is the seismicity-suppression front.

[20], we see little evidence for a different seismic response when $\mathrm{CO}_{2}$ rather than water is the injected fluid.

Besides examining event locations and magnitudes, Verdon et al. [20] used shear-wave splitting to image the induced fracture networks. Although not robustly constrained, inversions based on the SWS measurements appeared to show that the fracture network created during water injection was slightly more intense. This may account for what differences are there in formation permeability between supercritical $\mathrm{CO}_{2}$ and water-gel injection, as estimated by the porepressure method. However, the permeability estimates for the fractured formation (i.e., based on diffusivity estimate $D_{1}$ ) would suggest that both fluids generate similar fracture density. One possible explanation for the difference might be in terms of the size of fractures generated. The watergel treatment may generate large fractures that are effectively constant in dimension (e.g., displaying a Gaussian distribution), whereas the supercritical $\mathrm{CO}_{2}$ treatment may generate fewer large fractures yet many smaller fractures (i.e., skewed distribution). Based on the geometry of the microseismic monitoring array, the detectability limitations would be biased towards larger fractures. This would certainly explain the lower number of events recorded from the supercritical $\mathrm{CO}_{2}$ injection yet similar fractured formation permeability.

\section{Discussion and Conclusions}

We examined two approaches of estimating formation permeability using microseismic data: the pore-pressure triggering and the seepage-force triggering mechanisms. Based on microseismic data from a hydraulic fracture experiment injecting water and supercritical $\mathrm{CO}_{2}$ during different stages, we compared permeability estimates between the two approaches. The two hydraulic stimulation treatments were performed separately on two formation intervals having similar geological, geomechanical, and in situ stress conditions and only differed in terms of the injection fluid used. Both approaches (pore-pressure triggering and the seepageforce triggering) provided estimates of permeability within 
the same order of magnitude. However, the seepage-force mechanism (i.e., effective stress perturbation) provided more consistent estimates of permeability between the two different injection fluids.

Urbancic et al. [24] monitored significant microseismicity during a field test injecting 10,000 tons $\mathrm{CO}_{2}$ over a period of one month. They observed that microseismicity can be used to identify the position of the $\mathrm{CO}_{2}$ plume, and, although microseismicity was significant, there was no evidence of reduced cap rock integrity. Verdon et al. [25] demonstrated the added benefit of microseismic monitoring for the geological storage of $\mathrm{CO}_{2}$ during injection, where, for example, it was shown that microseismic activity is a natural consequence of fluid production and injection and does not necessarily imply leakage from the storage formation. Our results show that permeability estimates based on the seepage-force triggering mechanism technique using microseismic monitoring have strong potential to constrain formation permeability limitations for large-scale $\mathrm{CO}_{2}$ injection.

\section{Acknowledgments}

The authors would like to thank Pinnacle Technologies Ltd. for making the microseismic data available and Alexander Rozhko for providing the Matlab scripts to compute the seepage-force curves. This research was partially funded by the BUMPS consortium, UK Energy Research Center (UKERC), and Research Councils UK (RCUK). J. P. Verdon is a Natural Environment Research Council (NERC) EarlyCareer Research Fellow (Grant no. NE/I021497/1).

\section{References}

[1] J. R. Jones and L. K. Britt, Design and Appraisal of Hydraulic Fractures, SPE, Richardson, Tex, USA, 1997.

[2] N. Teanby, J. M. Kendall, R. H. Jones, and O. Barkved, "Stressinduced temporal variations in seismic anisotropy observed in microseismic data," Geophysical Journal International, vol. 156, no. 3, pp. 459-466, 2004.

[3] J. P. Verdon, J. M. Kendall, and A. Wüstefeld, "Imaging fractures and sedimentary fabrics using shear wave splitting measurements made on passive seismic data," Geophysical Journal International, vol. 179, no. 2, pp. 1245-1254, 2009.

[4] A. Wuestefeld, O. Al-Harrasi, J. P. Verdon, J. Wookey, and J. M. Kendall, "A strategy for automated analysis of passive microseismic data to image seismic anisotropy and fracture characteristics," Geophysical Prospecting, vol. 58, no. 5, pp. 755-773, 2010.

[5] A. McGarr, "Violent deformation of rock near deep-level tabular excavations-seismic events," Bulletin of the Seismological Society of America, vol. 61, pp. 1453-1466, 1971.

[6] C. I. Trifu, D. Angus, and V. Shumila, "A fast evaluation of the Seismic moment tensor for Induced Seismicity," Bulletin of the Seismological Society of America, vol. 90, no. 6, pp. 1521-1527, 2000.

[7] A. Al-Anboori, M. Kendall, D. Raymer, and R. Jones, "Spatial variations in microseismic focal mechanisms, Yibal Field, Oman," in Proceedings of the 68th EAGE Conference \& Exhibition, June 2006.

[8] S. A. Shapiro, Microseismicity: A Tool for Reservoir Characterization, EAGE Publications, Houten, The Netherlands, 2008.
[9] V. Grechka, P. Mazumdar, and S. A. Shapiro, "Predicting permeability and gas production of hydraulically fractured tight sands from microseismic data," Geophysics, vol. 75, no. 1, pp. B1-B10, 2010.

[10] S. A. Shapiro, J. Kummerow, C. Dinske et al., "Fluid induced seismicity guided by a continental fault: injection experiment of 2004/2005 at the German Deep Drilling Site (KTB)," Geophysical Research Letters, vol. 33, no. 1, Article ID L01309, 2006.

[11] A. Y. Rozhko, "Role of seepage forces on seismicity triggering," Journal of Geophysical Research B, vol. 115, no. 11, Article ID B11314, 2010.

[12] M. A. Biot, "Mechanics of deformation and acoustic propagation in porous media," Journal of Applied Physics, vol. 33, no. 4, pp. 1482-1498, 1962.

[13] S. Crampin and S. Peacock, "A review of shear-wave splitting in the compliant crack-critical anisotropic Earth," Wave Motion, vol. 41, no. 1, pp. 59-77, 2005.

[14] W. Narr, D. W. Schechter, and L. B. Thompson, Naturally Fractured Reservoir Characterization, SPE, Richardson, Tex, USA, 1997.

[15] M. D. Zoback and H. P. Harjes, "Injection-induced earthquakes and crustal stress at $9 \mathrm{~km}$ depth at the KTB deep drilling site, Germany," Journal of Geophysical Research B, vol. 102, no. 8, pp. 18477-18491, 1997.

[16] K. Terzaghi, Theoretical Soil Mechanics, John Wiley \& Sons, New York, NY, USA, 1943.

[17] E. J. Kaiser, A study of acoustic phenomena in tensile test [Doctoral thesis], Technische Hochschule München, Munich, Germany, 1959.

[18] L. Eisner, P. M. Duncan, W. M. Heigl, and W. R. Keller, "Uncertainties in passive seismic monitoring," Leading Edge, vol. 28, no. 6, pp. 648-655, 2009.

[19] P. J. Usher, D. A. Angus, and J. P. Verdon, "Influence of a velocity model and source frequency on microseismic waveforms: some implications for microseismic locations," Geophysical Prospecting. In press.

[20] J. P. Verdon, J. M. Kendall, and S. C. Maxwell, "A comparison of passive seismic monitoring of fracture stimulation from water and $\mathrm{CO}_{2}$ injection," Geophysics, vol. 75, no. 3, pp. MA1-MA7, 2010.

[21] S. C. Maxwell, J. Shemata, E. Campbell, and D. Quirk, "Microseismic deformation rate monitoring," in Proceedings of the SPE Annual Technical Conference and Exhibition (ATCE '07), pp. 2124, Denver, Colo, USA, September 2008.

[22] U. Zimmer, S. Maxwell, C. Waltman, and N. Warpinski, "Microseismic monitoring quality-control (QC) reports as an interpretative tool for nonspecialists," in Proceedings of the SPE Annual Technical Conference and Exhibition (ATCE '07), pp. 3074-3080, Anaheim, Calif, USA, November 2007.

[23] L. P. Dake, The Practice of Reservoir Engineering, Elsevier, London, UK, 2001.

[24] T. I. Urbancic, J. Daugherty, S. Bowman, and M. Prince, "Microseismic monitoring of a carbon sequestration field test," in Proceedings of the 2nd EAGE Passive Seismic Workshop, Limassol, Cyprus, 2009.

[25] J. P. Verdon, J. M. Kendall, D. J. White, and D. A. Angus, "Linking microseismic event observations with geomechanical models to minimise the risks of storing $\mathrm{CO}_{2}$ in geological formations," Earth and Planetary Science Letters, vol. 305, no. 1-2, pp. 143-152, 2011. 

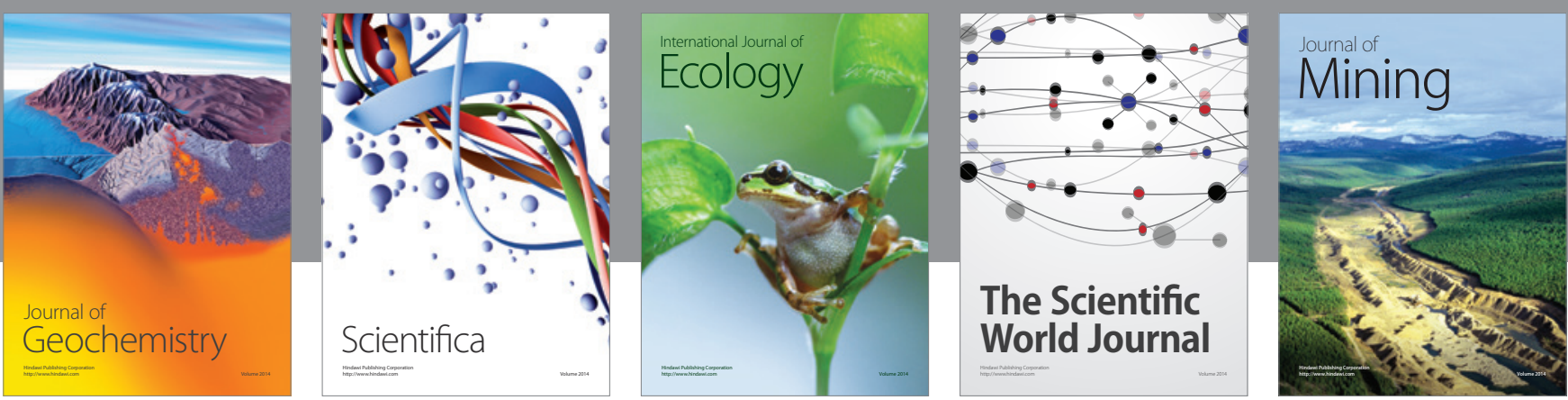

The Scientific World Journal
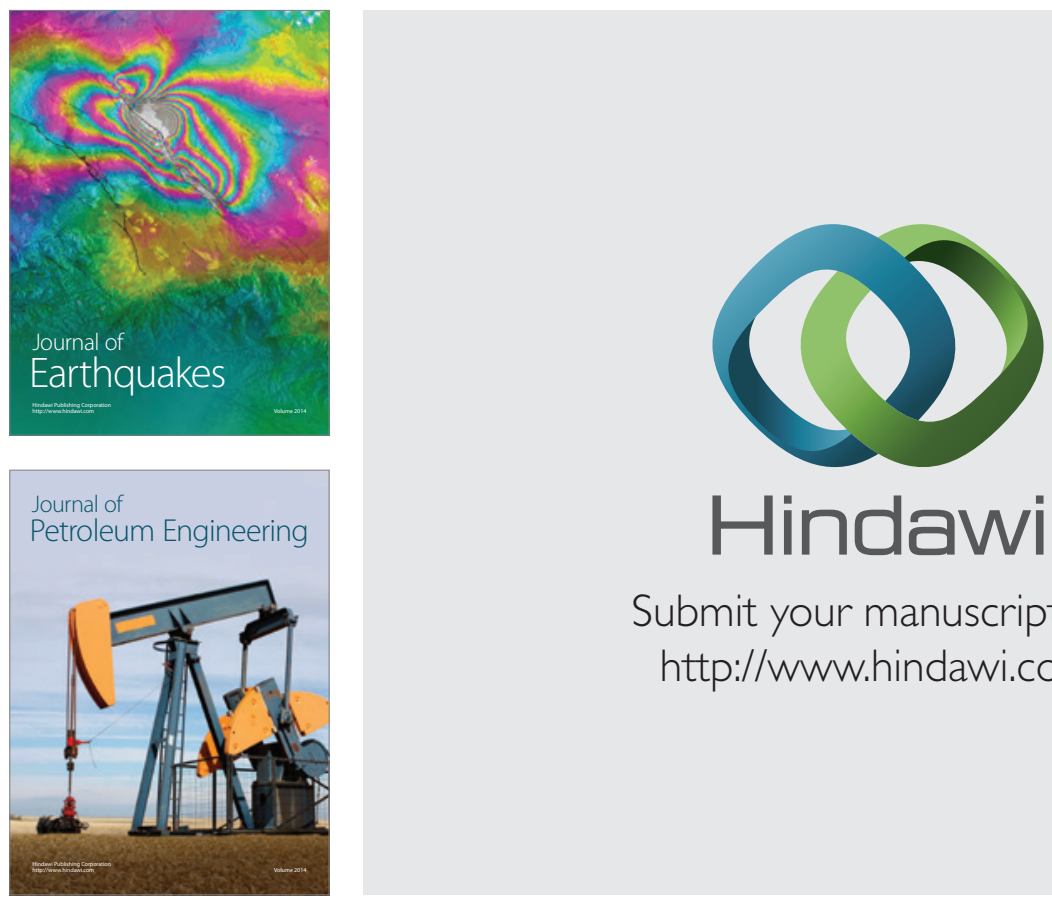

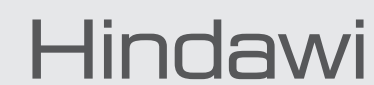

Submit your manuscripts at

http://www.hindawi.com
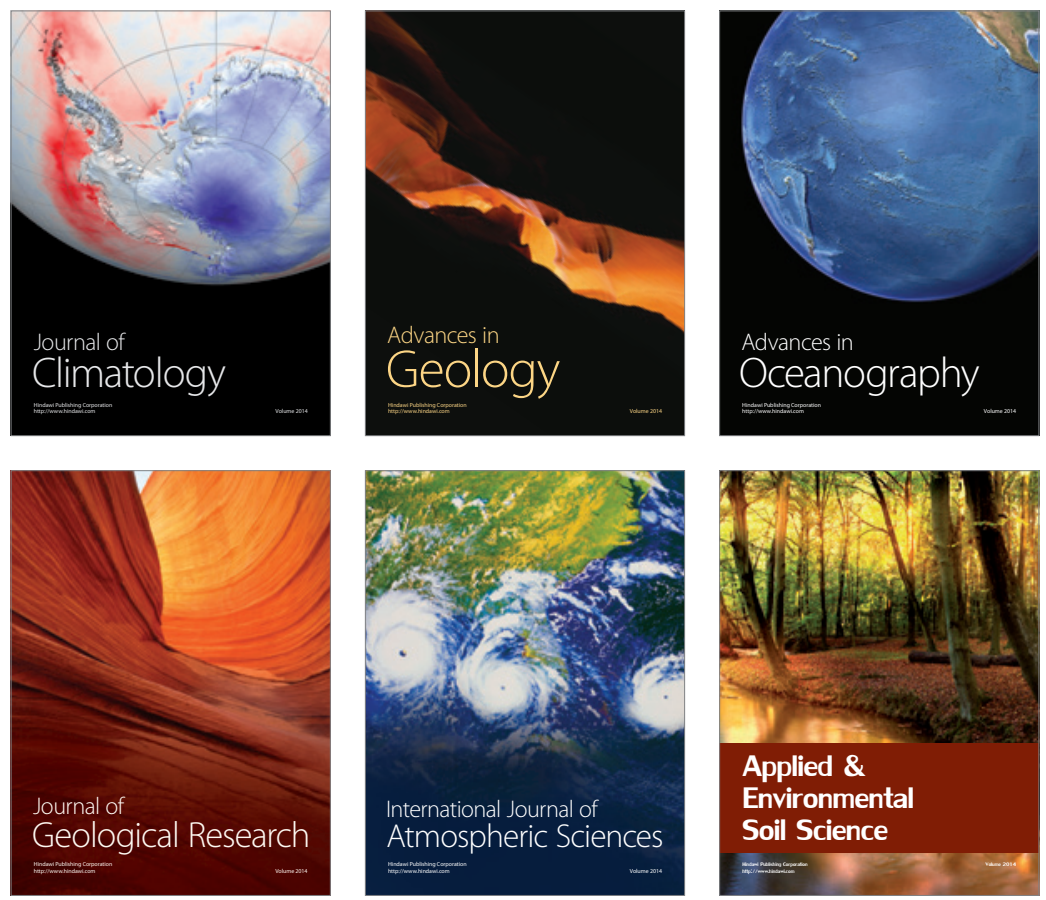
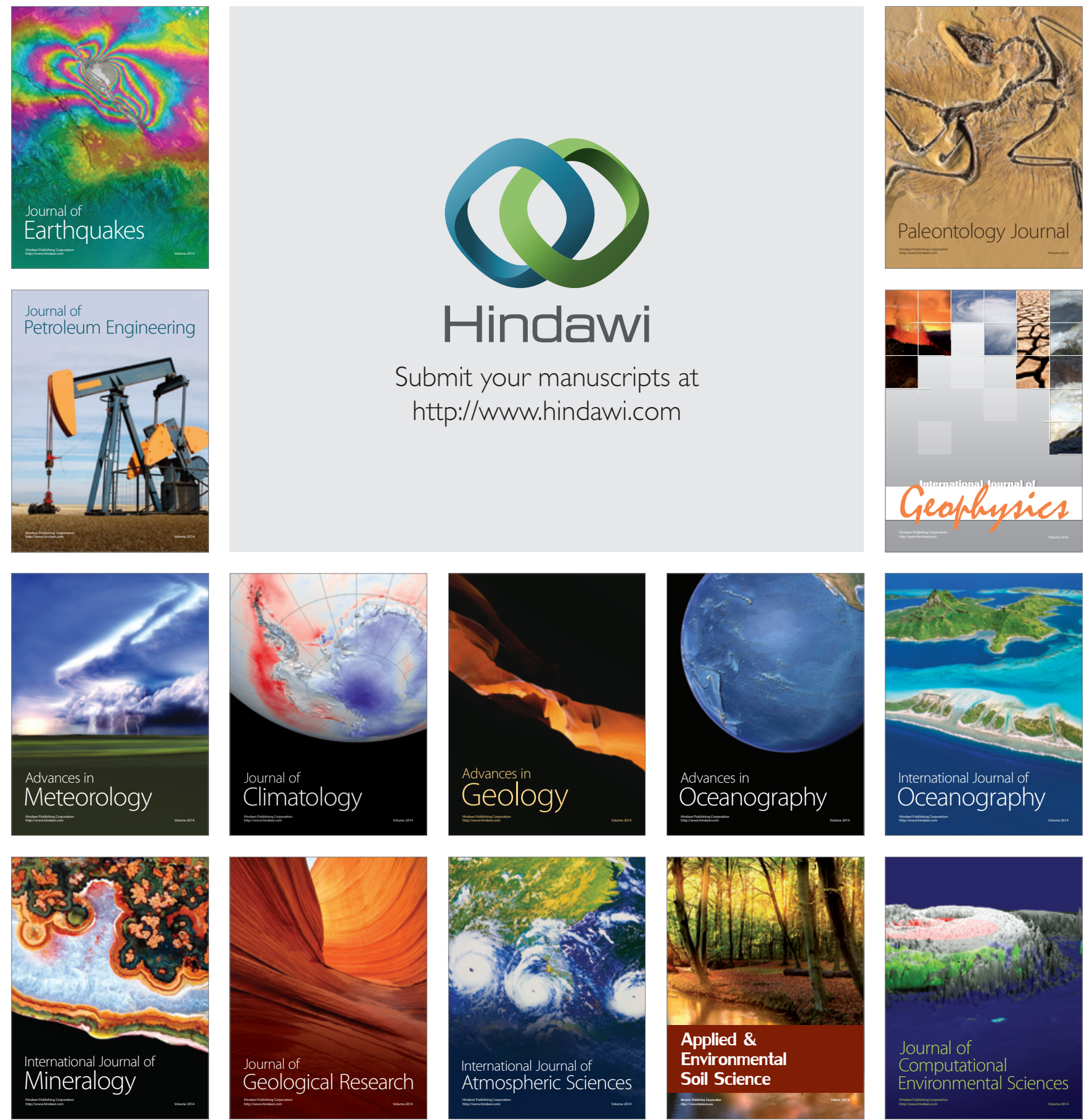